\title{
Critical Role of Hepatic Cyp450s in the Testis-Specific Toxicity of (5R)-5-Hydroxytriptolide in C57BL/6 Mice
}

\author{
Cunzhi Yu ${ }^{1,2}, Y u L_{i}^{1,2}$, Mingxia Liu ${ }^{1,2}$, Man Gao ${ }^{1,2}$, Chenggang $L^{1,2}$, Hong Yan ${ }^{1,2}$, \\ Chunzhu $\mathrm{Li}^{1,2}$, Lihan Sun ${ }^{3}$, Liying $\mathrm{Mo}^{3}$, Chunyong $\mathrm{Wu}^{3}$, Xinming $\mathrm{Qi}^{1,{ }^{2 *}}$ and Jin Ren ${ }^{1,2}$ \\ ${ }^{1}$ Center for Drug Safety Evaluation and Research, State Key Laboratory of Drug Research, Shanghai Institute of Materia \\ Medica, Chinese Academy of Sciences, Shanghai, China, ${ }^{2}$ University of Chinese Academy of Sciences, Beijing, China, \\ ${ }^{3}$ Department of Pharmaceutical Analysis, China Pharmaceutical University, Nanjing, China
}

Low solubility, tissue accumulation, and toxicity are chief obstacles to developing triptolide derivatives, so a better understanding of the pharmacokinetics and toxicity of triptolide derivatives will help with these limitations. To address this, we studied pharmacokinetics and toxicity of (5R)-5-hydroxytriptolide (LLDT-8), a novel triptolide derivative immunosuppressant in a conditional knockout (KO) mouse model with liver-specific deletion of CYP450 reductase. Compared to wild type (WT) mice, after LLDT-8 treatment, KO mice suffered severe testicular toxicity (decreased testicular weight, spermatocytes apoptosis) unlike WT mice. Moreover, KO mice had greater LLDT-8 exposure as confirmed with elevated AUC and Cmax, increased drug half-life, and greater tissue distribution. $\gamma-\mathrm{H} 2 \mathrm{AX}$, a marker of meiosis process, its localization and protein level in testis showed a distinct meiosis block induced by LLDT-8. RNA polymerase II (Pol II), an essential factor for RNA storage and synapsis in spermatogenesis, decreased in testes of KO mice after LLDT-8 treatment. Germ-cell line based assays confirmed that LLDT-8 selectively inhibited Pol II in spermatocyte-like cells. Importantly, the analysis of androgen receptor (AR) related genes showed that LLDT-8 did not change AR-related signaling in testes. Thus, hepatic CYP450s were responsible for in vivo metabolism and clearance of LLDT-8 and aggravated testicular injury may be due to increased LLDT-8 exposure in testis and subsequent Pol II reduction.

Keywords: (5R)-5-hydroxytriptolide, functional knockout, cytochrome P450, testes, $\gamma$-H2AX, RNA polymerase II, androgen receptor

\section{INTRODUCTION}

Triptolide is a structurally unique diterpenoid from Tripterygium wilfordii Hook F, and has excellent efficiency against cancers, polycystic kidney disease and rheumatic disease (Leuenroth and Crews, 2008; Zheng et al., 2008; Leuenroth et al., 2010; Mujumdar et al., 2010; Pan, 2010; Liu, 2011; Liu et al., 2011, 2013a,b; Manzo et al., 2012; Kim et al., 2014; Lu et al., 2014; Sangwan et al., 2015; Fan et al., 2016). By inhibiting XPB via covalent binding, a DNA helicase and a component of the TFIIH transcription complex, triptolide induced transcription repression and Pol II degradation in cancer cells (Titov et al., 2011; Chen et al., 2015). Other mechanisms such as Hsp70 inhibition, JNK and NF-kB signal pathways may also play a role (Villicana et al., 2013; Sangwan et al., 2015; Zhang et al., 2016). Triptolide inhibits dCTP pyrophosphatase 
activity, converting CTP to dCMP with a non-covalent interaction, and attenuates cystic kidney disease (Corson et al., 2011).

Lack of aqueous solubility, general toxicity, and tissue accumulation limited the clinical use of triptolide (Ye et al., 2010; Sun et al., 2013; Zhuang et al., 2013; Kong et al., 2015; Ma et al., 2015; Patil et al., 2015; Qi et al., 2015; Wang et al., 2016a,b, 2017; Ruan et al., 2017). Overexposure and subsequent toxicity of triptolide lead to the clinical trial termination of F6008, a prodrug of triptolide (Fidler et al., 2003; Kitzen et al., 2009). While the incomplete cleavage, loss of drug bioactivity and interpatient variability stopped the clinical trials of other prodrugs of triptolide, PG490-88, and omtriptolide (Kitzen et al., 2009). Therefore, clarifying the connection between toxicity and pharmacokinetics of triptolide and its derivatives may help us overcome some limitations of triptolide and allow the clinical use of triptolide and its derivatives (Zhou et al., 2012).

(5R)-5-hydroxytriptolide (LLDT-8) is a novel triptolide derivative with potent immunosuppressive, anti-inflammatory, and anticancer activity (Zhou et al., 2005; Wang et al., 2012; Zeng et al., 2016; Su et al., 2017), and it is now in phase II clinical trials in China for the treatment of rheumatoid arthritis (Qi et al., 2016). LLDT- 8 reduces the production of Th1 type cytokines (IFN- $\gamma$, IL-2) and inflammatory cytokines (TNF- $\alpha$, IL-16), and inhibits NF-kB activation triggered by lipopolysaccharide (Zhou et al., 2006a,b). LLDT-8 also has potent anticancer activity via transcription inhibition (Wang et al., 2012).

Compared to triptolide (Xue et al., 2011), LLDT-8 has a better safety profile and does not induce abnormalities in the epididymis, liver, kidney, spleen, or circulation (Qi et al., 2016). The testicular injury is the main adverse effect of LLDT- 8 in rodents, and recently we reported that spermatocytes are the primary target for LLDT-8 in the testes. Dephosphorylating TGF$\beta$ activated kinase (Tak1) Ser412 contributes to this selectivity (Qi et al., 2016). However, the interaction between toxicity and pharmacokinetics of LLDT-8 remained unknown.

The functional redundancy of CYP450 makes it difficult to determine the isoforms involved in drug metabolism and toxicity. $\mathrm{Wu}$ et al. developed a liver-specific knockout mouse model of cytochrome $\mathrm{P} 450$ reductase (Cpr), the sole electron donor of CYP450s, to overcome these limitations and reduced almost 95\% hepatic CYP450 activity (Wu et al., 2003). Cpr knockout inhibited the hepatic P450-dependent metabolism of monocrotaline, aristolochic acid, and triptolide (Xiao et al., 2008; Xue et al., 2011; Yao et al., 2014).

Here, this study compared the toxicity and tissue distribution of LLDT-8 between Cpr knockout and wildtype mice. Inactivation of hepatic cyp450s increased the exposure of LLDT8 and blocked meiosis in the testes by selectively downregulating $\gamma$-H2AX and RNA polymerase II in spermatocytes.

\section{MATERIALS AND METHODS}

\section{Chemicals}

(5R)-5-hydroxytriptolide (LLDT-8, 99.9\%) was from by Professor Yuanchao Li (Shanghai Institute of Materia Medica, Shanghai, China). All other chemicals were commercially available and purchased as reagent grade from Sigma-Aldrich (St. Louis, USA). The following antibodies were used for western blotting: $\gamma$-H2AX (Cat. No: 2577, Lot. No: 11, CST, USA), RNA polymerase II (Cat. No: 05-623, Lot. No: 2397109, Millipore, USA), $\beta$-actin (Cat. No: sc-47778, Lot. No: 2533, Santa Cruz, USA). $\gamma$-H2AX (Cat. No: ab26350, Lot. No: GR305763-3, Abcam, USA) was used for immunofluorescence assay.

\section{Animal Treatments}

Animal use protocols were approved by the Institutional Animal Care and Use Committee of the Shanghai Institute of Materia Medica (Shanghai, China), IACUC No. 2016-10-RJ-136. The Cpr knockout (KO) mice were a gift from Professor Xinxin Ding (Wadsworth Center, Albany, NY, USA). Procedures for animal breeding and genotyping were reported previously (Wu et al., 2005). Eight to twelve weeks old male KO mice and their WT littermates on a mixed C57BL/6 and 129/Sv genetic background were used in this study. All animals were provided with a certified standard diet and tap water ad libitum during experiments. All animals were maintained under controlled temperature with a $12 \mathrm{~h}: 12 \mathrm{~h}$ light/dark cycle. All efforts were made to minimize animal discomfort and illness, and mice were anesthetized with pentobarbital sodium (150 mg/kg, i.p.) before sample collection. No animals died during the experiment.

\section{Toxicological Study}

The $\mathrm{LD}_{50}$ of LLDT- 8 was $9.3 \mathrm{mg} / \mathrm{kg}$ (p.o.) in mice (Zhou et al., 2005), and we used a more clinically relevant dose in our animal experiments. For toxicity experiments, mice ( $n=3$ /group) were treated with LLDT-8 $(0.5$ or $1.0 \mathrm{mg} / \mathrm{kg})$ consecutively administered by gavage for 15 days. Controls received saline. Mice were killed on the 15th-day post-administration and blood, liver, kidney, spleen, testes, and epididymis were collected. About $500 \mu \mathrm{L}$ blood samples were collected from the heart. The main lobe of the liver, kidney, spleen, and epididymis was fixed in $10 \%$ neutral buffered formalin for histological examination, and the left testicle was fixed in modified Davidson's buffer $(30 \%$ of a $37-40 \%$ solution of formaldehyde, $15 \%$ ethanol, $5 \%$ glacial acetic acid, and $50 \%$ distilled $\mathrm{H}_{2} \mathrm{O}$ ) for $16 \mathrm{~h}$ followed by $10 \%$ neutral buffered formalin for $24 \mathrm{~h}$ (Latendresse et al., 2002). Tissue sections were stained with hematoxylin and eosin (H\&E). Remaining tissues were stored at $-80^{\circ} \mathrm{C}$ for RNA and protein extraction.

Sera were assayed for Urea, creatine (CRE), alanine aminotransferase (ALT), and aspartate transaminase (AST) using an automatic HITACHI Clinical Analyzer Model 7080 (Hitachi High-Technologies Corporation, Tokyo, Japan). The intercoefficients of variability in this assay were $1.1 \%$ (ALT), $0.9 \%$ (AST), $1.2 \%$ (Urea) and 1.4\% (CRE). The intracoefficients of variability in this assay were $2.0 \%$ (ALT), $0.9 \%$ (AST), $1.2 \%$ (Urea) and 5.1\% (CRE).

\section{Toxicokinetics of LLDT-8 in Mice}

For toxicokinetic experiments, mice ( $n=5-6 /$ group for each time point) were treated with a single dose of LLDT- 8 at ( 0.5 or $1.0 \mathrm{mg} / \mathrm{kg}$ ) by oral gavage, creating 4 treatment groups: $0.5 \mathrm{mg} / \mathrm{kg}$ 
LLDT-8-treated WT and KO mice, and $1.0 \mathrm{mg} / \mathrm{kg}$ LLDT-8treated WT and KO mice. After LLDT- 8 treatment, $20 \mu \mathrm{L}$ blood samples were collected at 5, 10, 20, 30, 45, 60, 90, 120, and $180 \mathrm{~min}$ from tail vein. Plasma was separated by centrifugation at 3,000 rpm for $5 \mathrm{~min}$ and kept at $-80^{\circ} \mathrm{C}$ until analysis. Tissues including the liver, kidney, testes, and epididymis were also collected from individual mice at 30 and $180 \mathrm{~min}$ after dosing and were weighed and homogenized in saline $(1.0 \mathrm{~g}$ wet weight $/ \mathrm{mL})$ on ice. LLDT8 was then extracted from the plasma or the tissue homogenates with an equal volume of ethyl acetate and dried under nitrogen. The residues were reconstituted in $50 \mu \mathrm{L}$ of mobile phase for analysis.

The quantification of LLDT-8 in samples was performed on Shimadzu 20A HPLC system (Shimadzu, Kyoto, Japan) equipped with an autosampler coupled to Shimadzu 8030 triple quadrupole mass spectrometer (Shimadzu, Kyoto, Japan). Separations were conducted under isocratic conditions. The mobile phase consisting of acetonitrile and water with $0.1 \%$ formic acid (50:50, v/v) was set at a flow rate of $0.2 \mathrm{~mL} / \mathrm{min}$. An electrospray interface in negative ionization mode was used. ESI source parameters were as followed: high purity dryinggas (N2) flow rate $8 \mathrm{~L} / \mathrm{min}$, temperature $400^{\circ} \mathrm{C}$, nebulizer pressure 25 psi. Multiple reaction monitoring (MRM) was used to quantify LLDT-8 (m/z 421.20 [M+COO]- $\rightarrow$ 45.10, fragmentor $110 \mathrm{eV}$, collision energy $-20 \mathrm{eV}$ ). Analytical data were processed using the labsolution software package (Shimadzu, Kyoto, Japan) consisting of qualitative and quantitative software.

Standard curves for LLDT-8 were prepared by spiking known amounts of the LLDT-8 standard into plasma or tissue homogenate samples prepared from untreated mice. LLDT- 8 concentrations in biological samples were determined by comparisons with standard curves. Pharmacokinetics were calculated using Kinetica software (version 4.4.1; Thermo Fisher Scientific Inc, Woburn, MA).

\section{Metabolic Profile of LLDT-8}

Metabolic profiles of LLDT-8 in liver microsomes from WT and $\mathrm{KO}$ mice were compared. In brief, $1 \mathrm{mM} \mathrm{NADPH}$ (Cat. No: 10107824001, Lot. No: 20595625, Sigma, USA), $5 \mathrm{mM}$ $\mathrm{MgCl}_{2}, 10 \mu \mathrm{L}$ mouse liver microsomes $(20 \mathrm{mg} / \mathrm{mL}$, microsomes were prepared from the liver of mouse pretreated with 80 $\mathrm{mg} / \mathrm{kg}$ dexamethasone for 3 days), $4 \mu \mathrm{L}$ LLDT-8 (12.5-50 $\mu \mathrm{M})$ in a $100 \mathrm{mM}$ phosphate buffer $(\mathrm{pH} 7.4)$. There was a $3 \mathrm{~min}$ preincubation step at $37^{\circ} \mathrm{C}$ before initiating the reaction by adding the NADPH into the microsomal suspension. The reaction was stopped with ice-cold acetonitrile after $60 \mathrm{~min}$ incubation. Identification of LLDT-8 metabolites was performed on an Agilent 1200 HPLC system (Agilent technologies Inc, Palo Alto, CA) equipped with a CTC PAL autosampler coupled to an API4000 QTRAP LC-MS/MS system (Thermo Fisher Scientific, USA). Separations were conducted under gradient conditions. The mobile phase consisting of $0.1 \%$ formic acid in acetonitrile and $0.1 \%$ formic acid in water (50:50, v/v) was set at a flow rate of $0.6 \mathrm{~mL} / \mathrm{min}$. An electrospray interface in negative ionization mode was used. ESI source parameters were as followed: high purity drying-gas $\left(\mathrm{N}_{2}\right)$ flow rate $8 \mathrm{~L} / \mathrm{min}$, temperature $550^{\circ} \mathrm{C}$, and nebulizer pressure 25 psi. Single ion monitoring with EMS/EPI scan mode was used to quantify LLDT-8 (positive: $\mathrm{m} / \mathrm{z} 377.1$, collision energy $60 \mathrm{eV}$; Negative: $\mathrm{m} / \mathrm{z}$ 375.1, collision energy $60 \mathrm{eV}$; negative: $\mathrm{m} / \mathrm{z}$ 375.1), and mono-hydroxylated LLDT-8 was selected with EPI scan mode (CE: $-45 \mathrm{v}, \mathrm{CES}:-15)$.

\section{Chemical Inhibition Study}

The chemical inhibition assay was performed as previously reported (Li et al., 2008). A $400 \mu$ l typical incubation mixture contained $0.2 \mathrm{mg}$ rat liver microsomes $(20 \mathrm{mg} / \mathrm{ml}$, Cat. No: LM-DS-02M, Lot. No: BDVH, Research Institute for liver Diseases, Shanghai, China), $2 \mu \mathrm{M}$ LLDT-8, $5 \mathrm{mM} \mathrm{MgCl}_{2}, 1 \mathrm{mM}$ NADPH (Cat. No: 10107824001, Lot. No: 20595625, Sigma, USA) and selective inhibitors of each CYP isoforms in a $100 \mathrm{mM}$ phosphate buffer ( $\mathrm{pH}$ 7.4). The inhibitors used were as follows: quercetin $(2 \mu \mathrm{M})$ for CYP1A and CYP2C8, 8-methoxypsoralen $(2.5 \mu \mathrm{M})$ for CYP2A6, sulfaphenazole $(10 \mu \mathrm{M})$ for CYP2C9, omeprazole $(20 \mu \mathrm{M})$ for CYP2C19, quinidine $(10 \mu \mathrm{M})$ for CYP2D6, clomethiazole $(50 \mu \mathrm{M})$ for CYP2E1, ketoconazole $(1 \mu \mathrm{M})$ for CYP3A4 and aminobenzotriazole $(50 \mu \mathrm{M}$, a broad CYP inhibitor) (Tsyrlov et al., 1994; Li et al., 2008). After incubation for $0,0.5$, and $1 \mathrm{~h}, 100 \mu \mathrm{l}$ supernatant was collected and quenched by the addition of $100 \mu \mathrm{l}$ of ice-cold acetonitrile. The mixtures were then centrifuged for $10 \mathrm{~min}$ at $20,000 \times \mathrm{g}$. An aliquot of the supernatant was analyzed by LC-MS/MS to monitor the residual LLDT-8 without extraction.

\section{Cell Culture}

Mouse GC-1spg (spermatogonia-like, ATCC number: CRL2053), TM4 (Sertoli cell-like, ATCC number: CRL-1715), and GC-2spd (spermatocyte-like, ATCC number: CRL-2196) were purchased from ATCC (Manassas, VA). Cells were grown in a $5 \% \mathrm{CO}_{2}$ atmosphere at $37^{\circ} \mathrm{C}$. TM4 was cultured in DMEM supplemented with 5\% horse serum, $2.5 \%$ fetal bovine serum and $1 x$ antibiotic-antimyotic (Cat. NO. 15240062, Life technologies). GC-1spg and GC-2spd were cultured in DMEM supplemented with $10 \%$ fetal bovine serum (Cat. No. F2442, Sigma, USA) and $1 x$ antibiotic-antimyotic (Cat.NO. 15240062, Life technologies).

\section{Quantitative Real-Time PCR (qPCR)}

Total mouse testes RNA was isolated using a UNIQ-10 total RNA isolation kit (Sangon Biotech, Shanghai, China). One micro gram RNA per sample was reverse-transcribed into cDNA using a PrimeScript RT reagent kit (Cat. No. RR036A, Takara, Dalian, China). The purity and quality of RNA and cDNA were checked by A260/A280 ratio and agarose gel. The qPCR was executed in $20 \mu \mathrm{L}$ volume containing $10 \mu \mathrm{L}$ SYBR Premix Ex Taq (Cat. No. RR820A, Takara, Dalian, China), $8 \mu \mathrm{L}$ of cDNA (80 ng cDNA), 1 $\mu \mathrm{L}$ forward primer $(500 \mathrm{nM})$ and $1 \mu \mathrm{L}$ reverse primer $(500 \mathrm{nM})$. The sequences of primers for Androgen-binding protein (ABP) and cystatin 12 (Cst12) were referenced from PrimerBank. The sequences for other genes were described elsewhere [Deleted in azoospermia-like (Dazl), Heat shock protein a2 (Hspa2), Phosphoglycerate kinase-2 (Pgk2), Protamine 1 (Prm1), GATA binding protein 1 (Gata1) and Zbtb16 zinc finger and BTB domain containing 16 (Plzf) (Qi et al., 2016); AR (Ma et al., 2013); Reproductive homeobox 5 (Rhox5) (Kurek et al., 2015); Fatty acid binding protein (FABP) (Vanschoonbeek et al., 2008); 
Claudin 11 (Cldn11) (Sumigray et al., 2014); $\beta$-actin (Wan et al., 2017)]. All the sequences of primers were listed in Table 1. The qPCR process was performed using a Rotor Gene Q PCR system (QIAGEN, Shanghai, China). The qPCR amplification program consisted of polymerase activation at $98^{\circ} \mathrm{C}$ for the $30 \mathrm{~s}$ and 40 cycles of denaturation at $95^{\circ} \mathrm{C}$ for $5 \mathrm{~s}$, annealing, and extension at $60^{\circ} \mathrm{C}$ for $40 \mathrm{~s}$. The melting curve analysis was carried out for each reaction from 50 to $99^{\circ} \mathrm{C}$. The $\mathrm{CT}$ values for the samples were normalized to the corresponding $\beta$-actin CT values.

\section{Western Blot Analysis}

Cells were washed twice with ice-cold PBS (137 mM NaCl, $2.7 \mathrm{mM} \mathrm{KCl}, 10 \mathrm{mM} \mathrm{Na}_{2} \mathrm{HPO} 4$, and $1.8 \mathrm{mM} \mathrm{KH}_{2} \mathrm{PO} 4, \mathrm{pH} 7.4$ ) and lysed in SDS sample buffer. Cell lysates, containing $20 \mu \mathrm{g}$ of protein, were separated with SDS-PAGE (8\%) and transferred to polyvinylidene difluoride membranes. After blocking in 5\% non-fat milk in tris-buffered saline containing $0.1 \%$ Tween-20 $(\mathrm{pH}=7.6)$, membranes were incubated with the appropriate primary antibodies at $4{ }^{\circ} \mathrm{C}$ overnight. The primary antibodies $\gamma$-H2AX (Cat. No: 2577, Lot. No: 11, CST, USA) and Pol II (Cat. No: 05-623, Lot. No: 2397109, Millipore, USA) diluted $1: 1000$ in $5 \%$ bovine serum albumin (BSA, Cat. No. B206450G, Sigma, USA). Then the membranes were exposed to secondary antibodies (1:10,000, Cat. No.111-035-003, 115-035003, Jackson ImmunoResearch Laboratories, USA) in 5\% non-fat

\begin{tabular}{|c|c|c|}
\hline Gene & Accession number & Primer sequences $\left(5^{\prime}-3^{\prime}\right)$ \\
\hline \multirow[t]{2}{*}{ Dazl } & NM_010021 & Forward:CCTCCAACCATGATGAATCC \\
\hline & & Reverse: TCTGTATGCTTCGGTCCACA \\
\hline \multirow[t]{2}{*}{ Hspa2 } & NM_008301 & Forward: CATCATCAATGAGCCCACAG \\
\hline & & Reverse:TCTTGTGTTGGGCTTGAAC \\
\hline \multirow[t]{2}{*}{ Pgk2 } & NM_031190 & Forward: CTGTTGCTGATGAGCTCAAG \\
\hline & & Reverse: ACTCCGACCATAGAACTGTG \\
\hline \multirow[t]{2}{*}{ Prm1 } & NM_013637 & Forward: ATGCTGCCGCAGCAAAAGCA \\
\hline & & Reverse: CACCTTATGGTGTATGAGCG \\
\hline \multirow[t]{2}{*}{ Gata1 } & NM_008089 & Forward: CAGGTTCTाTCCTCTGGG \\
\hline & & Reverse: AAAGGACTGGGAAAGTCAGC \\
\hline \multirow[t]{2}{*}{ Plzf } & NM_001033324 & Forward: TGAGATCCTCTTCCACCGAA \\
\hline & & Reverse: GTAGGACTCATGGCTGAGAGA \\
\hline \multirow[t]{2}{*}{ AR } & NM_013476 & Forward: CTGGGAAGGGTCTACCCAC \\
\hline & & Reverse: GGTGCTATGTTAGCGGCCTC \\
\hline \multirow[t]{2}{*}{ Rhox5 } & NM_008818 & Forward: ACTCGGAAGAACAGCATGATG \\
\hline & & Reverse: CCCTGGTGCCACTATCCTT \\
\hline \multirow[t]{2}{*}{ ABP } & NM_011367 & Forward: TCTGCTGTTGCTACTACTGATGC \\
\hline & & Reverse: GGGCCATTGCTGAGGTACTTA \\
\hline \multirow[t]{2}{*}{ FABP } & NM_024406 & Forward: AAGGTGAAGAGCATCATAACCCT \\
\hline & & Reverse: TCACGCCTTTCATAACACATTCC \\
\hline \multirow[t]{2}{*}{ Cst12 } & NM_027054 & Forward: CGTGTTCCACTTCAACGAAAAC \\
\hline & & Reverse: GCCCATCTCCAGGTCTACTAAAT \\
\hline \multirow[t]{2}{*}{ Cldn11 } & NM_008770 & Forward: ATGGTAGCCACTTGCCTTCAG \\
\hline & & Reverse: AGTTCGTCCATIITCGGCAG \\
\hline \multirow[t]{2}{*}{$\beta$-actin } & NM_007393 & Forward: GCATTGCTGACAGGATGCAG \\
\hline & & Reverse: GAGCCACCGATCCACACAGA \\
\hline
\end{tabular}

milk for $1 \mathrm{~h}$ at room temperature. Immunoreactive proteins were visualized using an enhanced chemiluminescent system (Cat. No. WBKLS0500, Millipore, Shanghai, China).

\section{TUNEL}

TUNEL assays were performed according to the manufacturer's protocol (In Situ Cell Death Kit, Roche Diagnostics, Indianapolis, IN). In brief, the paraffin-embedded testis tissue samples were deparaffinized three times in exchanges wash of xylene. The testis sections were then gradually rehydrated using decreasing ethanol concentrations $(100,95,90,80$, and 70\%) followed by PBS $(\mathrm{pH}=7.4)$. After digestion with proteinase $\mathrm{K}(15 \mu \mathrm{g} / \mathrm{mL}$, Cat. No. 539480, Lot. No. D00148754, Millipore, USA), paraffinembedded tissue sections were labeled with a TUNEL reaction mixture, which contained terminal deoxynucleotidyl transferase incorporated with fluorescein. And $1 \mu \mathrm{g} / \mathrm{mL}$ DAPI (Sigma, USA) to used to reveal nuclear DNA. After staining, images were obtained with a fluorescent microscope (NIKON TS2, Japan).

\section{Immunofluorescence}

For immunofluorescence analysis, the paraffin-embedded testis tissue samples were deparaffinized three times in exchanges wash of xylene. The testis sections were then gradually rehydrated using decreasing ethanol concentrations followed by $\mathrm{PBS}(\mathrm{pH}=7.4)$. After antigen retrieval in boiling $0.1 \mathrm{M}$ citrate buffer $(\mathrm{pH}=6.0)$, the tissue sections were placed in humidity chambers and incubated with $4 \%$ BSA in PBS for $2 \mathrm{~h}$ at room temperature. Then 1:400 1\% BSA diluted $\gamma$ H2AX primary antibody (Cat. No: ab26350, Lot. No: GR3057633, Abcam, USA) and isotope control Mouse IgG1 (Cat. No: sc-3877, Lot. No: F1316, Santa Cruz, USA) was used. After incubated with primary antibody overnight at $4^{\circ} \mathrm{C}$, testis tissue samples were washed three times with PBS. Then the samples were incubated with 1:500 diluted secondary antibody (Alexa Fluor 594 (red)-conjugated Affinipure Donkey Antimouse IgG (Cat. No. 715-585-150, Life Technologies, USA) for $0.5 \mathrm{~h}$ at room temperature. And $1 \mu \mathrm{g} / \mathrm{mL}$ DAPI (Sigma, USA) to used to reveal nuclear DNA. After mounted in an antifade solution (Cat. No. S36963, Life Technologies, USA), tissue samples were observed using a confocal microscope (LEICA, USA).

\section{Statistical Analysis}

Statistical analysis was performed using two-tailed Student's $t$-tests or one-way ANOVA followed by LSD's post hoc test $(p<0.05$ was considered statistically significant).

\section{RESULTS}

\section{Knockout of Hepatic Cpr Aggravated Testicular Injury Induced by LLDT-8}

The dosage of LLDT- $8(0.5-1 \mathrm{mg} / \mathrm{kg})$ in this study was clinically relevant. Chronic administration of LLDT- 8 did not alter the body weight of WT and KO mice, but dosedependently reduced the testes (Figures 1A,B). The epididymis 

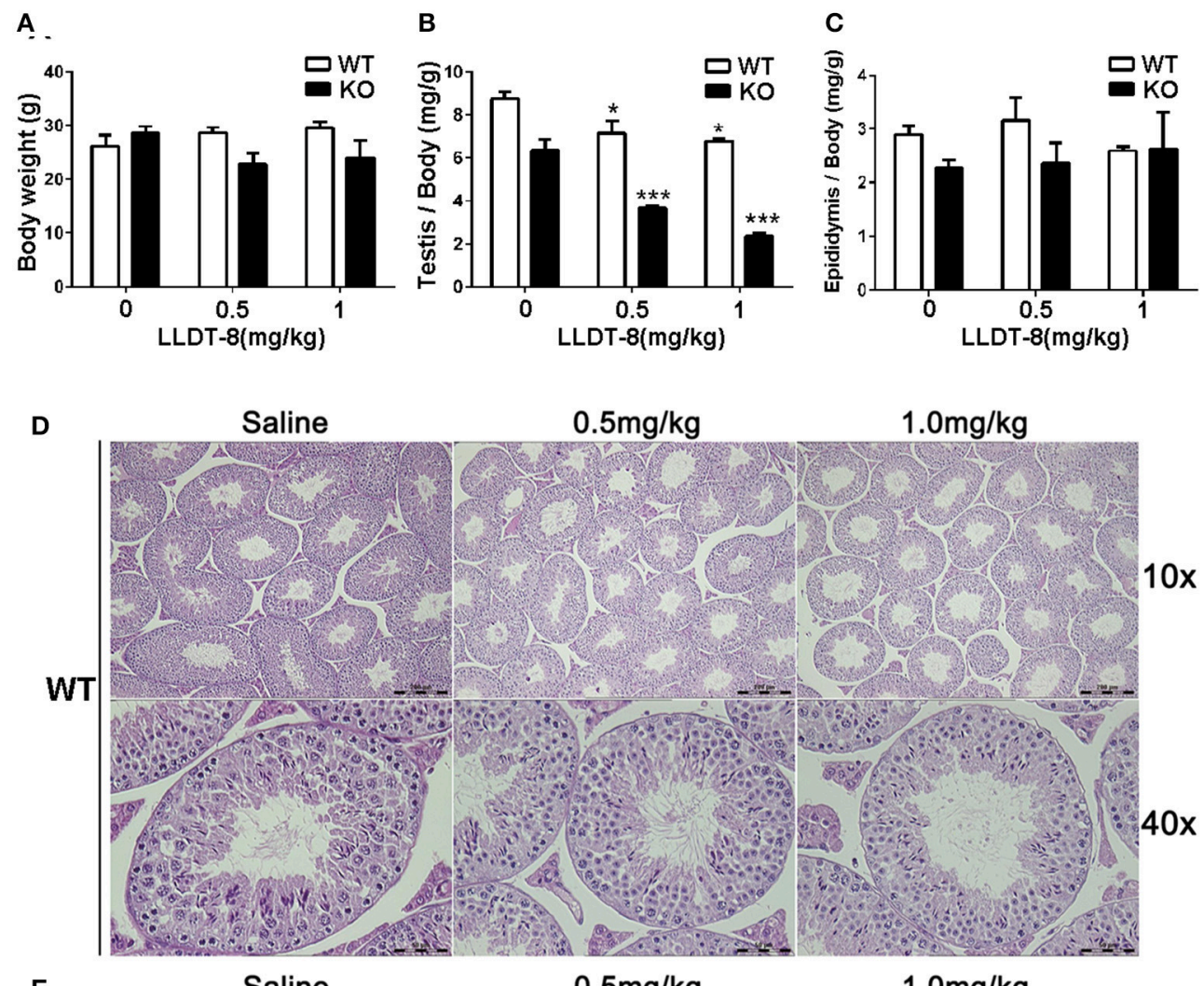

E

$0.5 \mathrm{mg} / \mathrm{kg}$

$1.0 \mathrm{mg} / \mathrm{kg}$

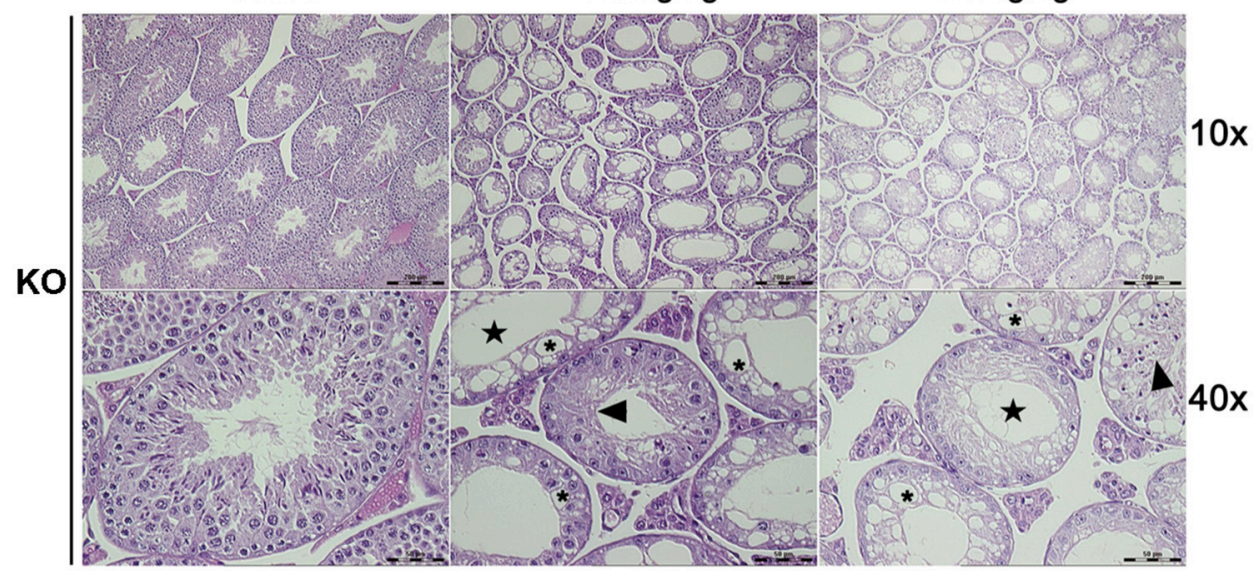

FIGURE 1 | Hepatic Cpr knockout aggravated LLDT-8 induced testicular injury. (A) Body weights of WT and KO mice; (B) Testis relative weight (absolute testis weight vs. body weight); (C) Epididymis relative weight (absolute epididymis weight vs. body weight); H\&E sections of the left testicle of WT (D) and KO (E) mouse ( $\times 10$, $\times 40)$; Star: reduction of germinal layers; Asterisk: vacuolar degeneration; Arrow: abnormally developed spermatids. Significant difference was determined by one way ANOVA, mean $\pm S D, n=3,{ }^{*} p<0.05,{ }^{* \star *} p<0.001$ vs. Saline group.

weight was not changed by LLDT-8 treatment LLDT-8 treatment (Figure 1C). Compared to WT mice, the testes in KO mice showed reduced germinal cell layers (Figures 1D,E, Star), severe vacuolar degeneration (Figure 1E, asterisk) and absence of spermatids development (Figure 1E, arrow). TUNEL assay found the number of TUNEL positive foci in $\mathrm{KO}$ mice testis were much higher than that in WT mice (Figures 2A,B) after LLDT8 weight after LLDT- 8 treatment in WT mice, consistent with another experiments using C57BL/6 mice (Supplementary Figure S1A). Noticeably, compared to WT mice with saline, TUNELpositive foci in the testes of WT mice with LLDT- 8 treatment apparently increased (Figures $\mathbf{2 A}, \mathbf{C}$ ).

LLDT-8 also induced hematological change and enlarged spleen in KO mice (Supplementary Figure S2). LLDT-8 did not cause liver injury and kidney damage (Supplementary Figures S3, S4). 


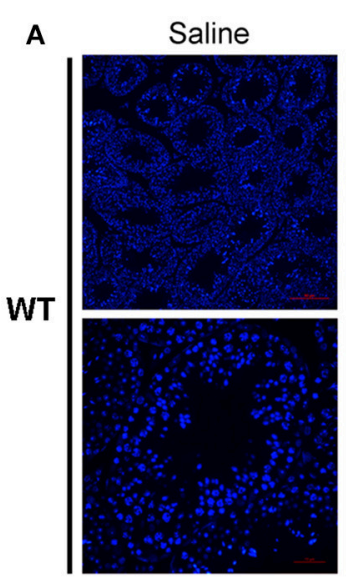

B

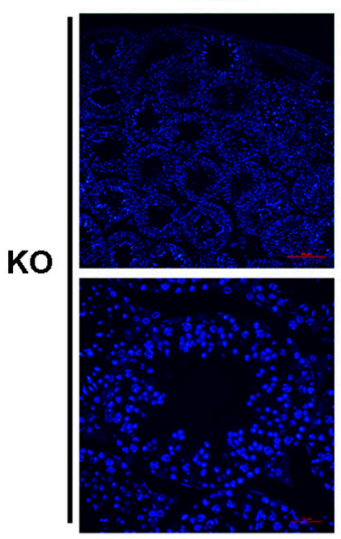

$0.5 \mathrm{mg} / \mathrm{kg}$
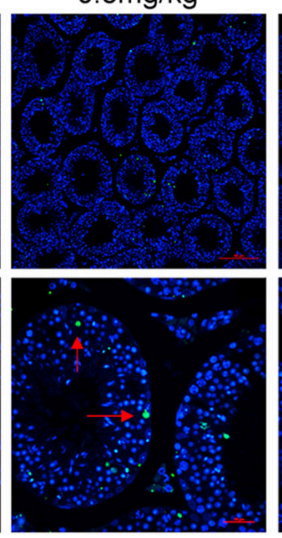

$0.5 \mathrm{mg} / \mathrm{kg}$

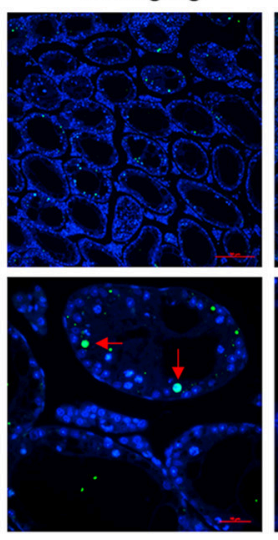

$1 \mathrm{mg} / \mathrm{kg}$

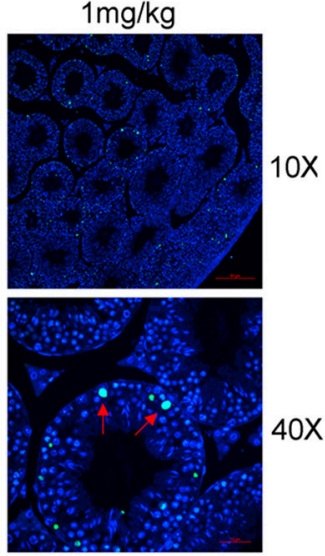

$1 \mathrm{mg} / \mathrm{kg}$

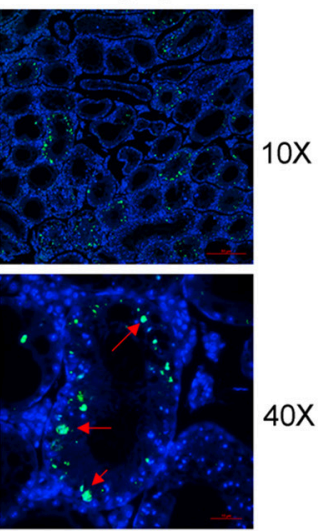

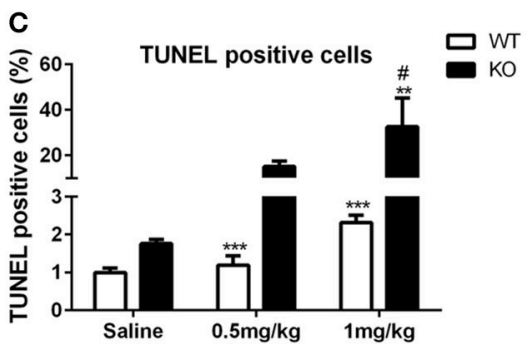

FIGURE 2 | TUNEL assay of LLDT-8 induced testis injury. The paraffin-embedded testis sections of WT (A) and KO (B) mice were labeled with TUNEL reaction mixture to distinguish the TUNEL positive cell $(\times 10, \times 40)$. Arrow: TUNEL positive cell. (C) Quantification of TUNEL positive cells. A significant difference was determined by one way ANOVA, mean $\pm S D, n=3,{ }^{* *} p<0.01,{ }^{* * *} p<0.001$ vs. Saline group, $\# p<0.05$ vs. WT mice at the same dosage.

\section{Inactivation of Hepatic CYP450 Increased the Exposure of LLDT-8}

WT and $\mathrm{KO}$ mice were treated with a single dose of LLDT-8 at $0.5 / 1.0 \mathrm{mg} / \mathrm{kg}$ by oral gavage. There is a significant increase in half-life (1.9 folds to WT mice), $\mathrm{C}_{\max }$ (1.9 folds to WT mice) and AUC (3.1 folds to WT mice) of LLDT- 8 in KO mice, accompanied by a marked decrease in the clearance, compared to those in WT mice (Figures 3A,B; Table 2). LLDT8 levels in liver, kidney, testis, and epididymis of $\mathrm{KO}$ mice were about 2-3 folds higher than those of WT mice at $30 \mathrm{~min}$ following a dose of LLDT-8 treatment at $1.0 \mathrm{mg} / \mathrm{kg}$ (Figure 3C).

Hepatic microsomes isolated from the liver of WT and KO mice were used to identify the potential metabolites of LLDT-8. Based on our previous findings on triptolide (Xue et al., 2011), we hypothesized hydroxylation is an elimination route of LLDT8 in vivo. After 60 min-incubation, the recovered samples were subjected to API400 QTRAP LC-MS/MS system, single ion monitoring (SIM) with EMS/EPI scan mode was used to identify LLDT-8 (Negative: $\mathrm{m} / \mathrm{z}$ 375.1), mono-hydroxylated LLDT-8 (Negative: $\mathrm{m} / \mathrm{z}$ 391.1). Two mono-hydroxylated metabolites M1 and M2 $(\mathrm{m} / \mathrm{z}=391.1)$ were identified in the microsomal samples from WT mice, but not in those of $\mathrm{KO}$ mice (Figures 3D-F). The response of mass spectrometric response of M1 and M2 increased with the concentration of LLDT8 (Table 3). There were no di-hydroxylated metabolites of LLDT-8 $(\mathrm{m} / \mathrm{z}=407.1)$ were identified in both WT and KO mice.

To identify the CYP isoforms responsible for the metabolism of LLDT-8, various selective inhibitors of CYPs were employed (Figure 3G). The metabolism of LLDT-8 was inhibited by aminobenzotriazole (a broad CYP inhibitor), omeprazole (CYP2C19 inhibitor), quinidine (CYP2D6 inhibitor), clomethiazole (CYP2E1 inhibitor) and ketoconazole (CYP3A4 inhibitor) in rat liver microsomes.

\section{LLDT-8 Decreased the Expression and Changed the Distribution of $\gamma-\mathrm{H} 2 \mathrm{AX}$, a Marker of Meiosis}

To clarify the potential mechanisms of LLDT-8 induced testicular injury in $\mathrm{KO}$ mice, we examined the expression and distribution 
A

B
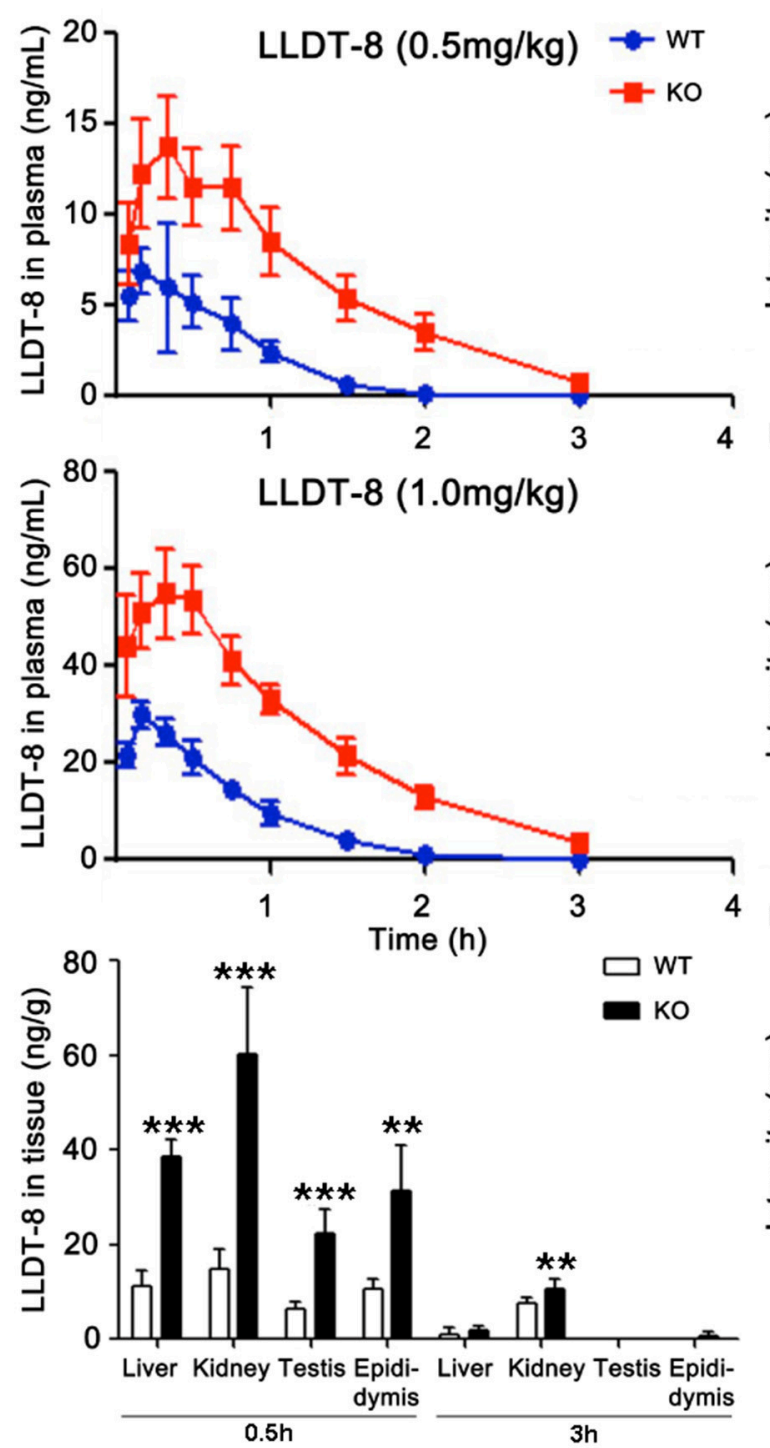

D

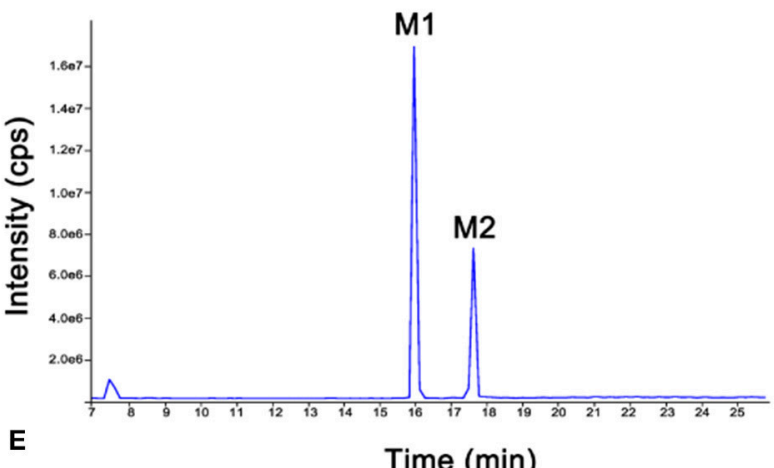

M1

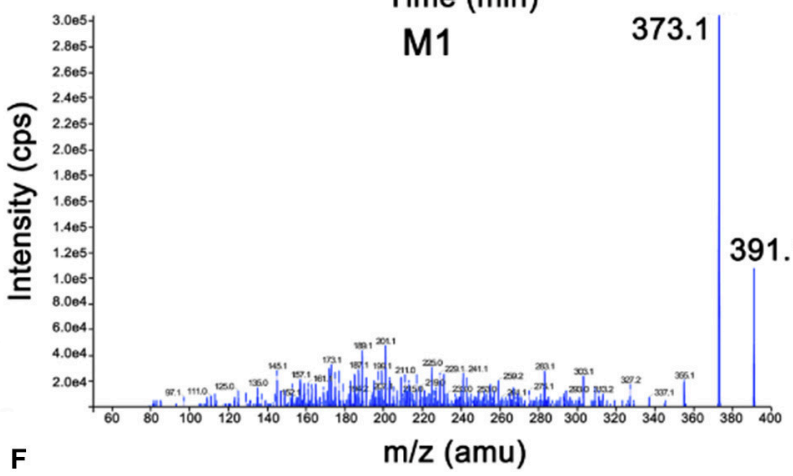

391.1

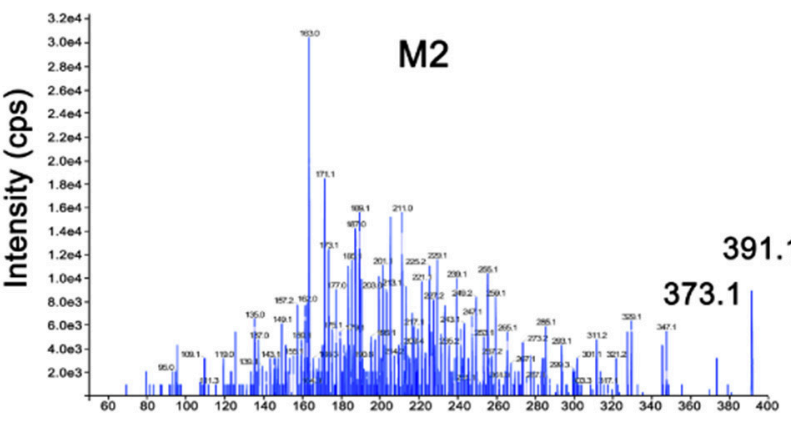

$\mathrm{m} / \mathrm{z}$ (amu)

G

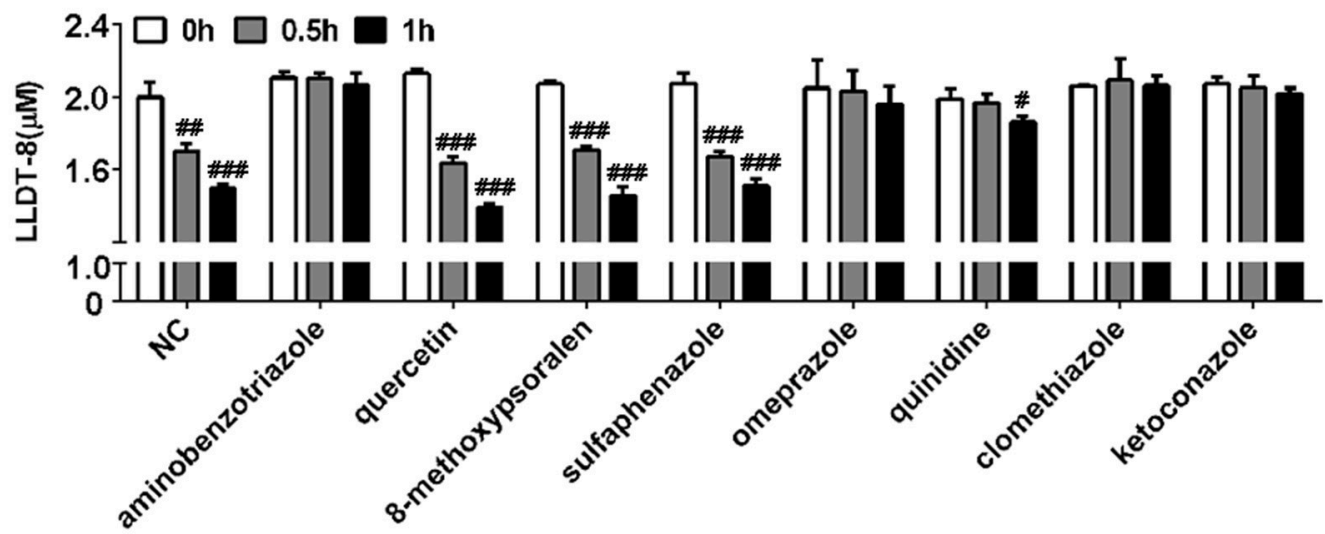

FIGURE 3 | Levels of LLDT-8 in the blood, liver, kidney, testis, and epididymis of KO and WT mice following a single oral dose of LLDT-8. Levels of LLDT-8 in the plasma from $0.5 \mathrm{mg} / \mathrm{kg}$ (A) and $1.0 \mathrm{mg} / \mathrm{kg}$ (B) group, and the LLDT-8 level in the liver, kidney testis, and epididymis (C) were determined by LC-MS/MS. ND, not detectable; mean $\pm S D, n=5$ for each time point, ${ }^{* \star} p<0.01,{ }^{* \star *} p<0.001 \mathrm{vs}$. WT $1.0 \mathrm{mg} / \mathrm{kg}, t$-test. (D) LLDT-8 metabolites (M1 and M2, $\left.\mathrm{m} / \mathrm{z} 391.1\right)$ were detected 
FIGURE 3 | Continued

in the microsomal samples from WT mice. Mass spectrometry of metabolite M1 (E) and M2 (F) were characterized by fargments $\mathrm{m} / \mathrm{z}$ 391.1-373.1. The retention time and peak area of each metabolite were summarized in Table 3. Inhibitory effects of CYP inhibitors on the metabolism of LLDT-8 in rat liver microsomes (G). LLDT-8 $(2 \mu \mathrm{M})$ was incubated with rat liver microsomes for 0.5 and $1 \mathrm{~h}$, the residual LLDT-8 was analyzed by LC-MS/MS, mean $\pm S D$, all incubations were carried out in three independent experiments in triplicate. $\#_{p}<0.05, \# \# p<0.01, \# \# \#_{p}<0.001$ vs. $0 \mathrm{~h}$.

TABLE 2 | Pharmacokinetic parameters for plasma LLDT-8 in WT and KO mice.

\begin{tabular}{|c|c|c|c|c|c|c|}
\hline & & $\mathrm{T} 1 / 2(\mathrm{~h})$ & $\mathbf{T}_{\max }$ (h) & $\mathbf{C}_{\max }(\mathbf{n g} / \mathbf{m l})$ & AUC ([ng/ml] $\times h)$ & CL(L/kg/h) \\
\hline \multirow[t]{2}{*}{ LLDT-8 } & WT & $0.31 \pm 0.03$ & $0.17 \pm 0.00$ & $29.95 \pm 2.81$ & $241.48 \pm 30.64$ & $4.13 \pm 0.53$ \\
\hline & $\mathrm{KO}$ & $0.59 \pm 0.06^{\star \star \star}$ & $0.33 \pm 0.11^{\star *}$ & $57.97 \pm 8.28^{\star \star \star}$ & $753.52 \pm 76.39^{\star \star \star}$ & $1.33 \pm 0.12^{\star \star \star}$ \\
\hline
\end{tabular}

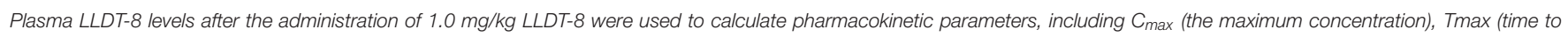
reach $C_{\max }$ ), AUC (area under the curve), T1/2 (the elimination half-life) and CL (oral clearance). Data are mean $\pm S D, n=5 .{ }^{* *} p<0.01,{ }^{* \star *} p<0.00 .1$ vs. WT group.

of $\gamma$-H2AX, a marker of meiosis and XY body formation in the testes of mice (Hamer et al., 2003; Noguchi et al., 2008; Ahmed et al., 2013). In WT and KO mice with saline, the nuclei distribution of $\gamma-\mathrm{H} 2 \mathrm{AX}$ indicated the presence of leptotene or zygotene spermatocytes, characterized by the ringlike property of seminiferous tubules, which was reduced in WT mice or even disappeared in the testes of $\mathrm{KO}$ mice after LLDT-8 treatment (Figures 4A,B). The XY bodies indicated by $\gamma$-H2AX foci (cloud like, yellow arrow) were normal in the testes of WT and KO mice with saline, while decreased in the testes of WT mice with $1.0 \mathrm{mg} / \mathrm{kg}$ LLDT- 8 and disappeared in the testes of $\mathrm{KO}$ mice treated with LLDT-8 (Figures 4E,F). Immunoblotting also confirmed the reduction of $\gamma-\mathrm{H} 2 \mathrm{AX}$ protein level in the testes but not in the liver (Figures 4C,D). These results strongly suggested that accumulated LLDT-8 may induce a severe meiotic block in the testes of $\mathrm{KO}$ mice.

We also detected other germ cell markers in the testes of WT and KO mice (Supplementary Figures S5, S6) and found a marked decrease of Dazl (a marker for type B spermatogonia and primary spermatocytes), Prm1 (a marker for spermatids) and a mild decrease of Hspa2 in the testes of WT mice (Supplementary Figure S5).

\section{LLDT-8 Selectively Decreased RNA Polymerase II of Spermatocytes}

In spermatogenesis, the formation of RNA granule and specific transcription activation at some genomic foci (including histone, piRNA.etc) are entirely dependent on RNA Polymerase II (Pol II) (Voronina et al., 2011; Pandey and Pillai, 2014). In KO mice, LLDT- 8 decreased Pol II protein in the testes and did not change its level in the livers (Figures 5A,B). In WT mice, the expression of Pol II in the testes and liver did not change significantly (Figures 5A,B). Three immortalized germ cell lines derived from mouse testes, spermatogonialike GC-1spg, Sertoli-like TM4, and spermatocyte-like GC2spd were used to evaluate the effects of LLDT-8. LLDT8 dose- and time-dependently reduced Pol II protein in GC-2spd cells, but not in GC-1spd and TM4 cell lines (Figures 5C-E).

\section{LLDT-8 Did Not Lessen the Expression of AR-Related Genes in Sertoli Cells}

Spermatogenesis is tightly regulated by androgen from Leydig cells and androgen receptor (AR) signaling in Sertoli cells (SCs) (Tan et al., 2005). Here, we selected AR-dependent two genes: Rhox5 and Cldn11 as the key indexs of ARrelated signaling in sertoli cells (Willems et al., 2010). We also selected AR-independent three genes: Cst12, ABP and FABP as the indexs of sertoli cell function (Johnston et al., 2004; Li et al., 2005; Tan et al., 2005). LLDT-8 treatment did not reduce the expression of all these genes including AR in the testes of WT mice (Figures 6A-F), while increased the expression of Cldn11, Cst12 and FABP, particularly in $1.0 \mathrm{mg} / \mathrm{kg}$ group.

\section{DISCUSSION}

Many efforts have been made to modify triptolide and overcome three major problems: low solubility, toxicity and tissue accumulation (Zhou et al., 2012). One of the outcomes is LLDT-8, (5R)-5-hydroxytriptolide, which shows a favorable safety profile and is well-tolerated in Phase I and II clinical trials in a female population (Supplementary Figure S1). The testicular injury is the major adverse effects in male rodents and dogs (data not shown). As the sole triptolide derivative entering Phase II clinical trial, it's well deserved to clarify the potential contribution of the pharmacokinetics of LLDT- 8 to its toxicity, which will be helpful to its Phase III clinical trial in various populations.

Compared to triptolide, LLDT- 8 has better pharmacokinetics properties than those of triptolide: lengthened Tmax and non-cumulative property (Xue et al., 2011). Unlike triptolide (Xue et al., 2011), LLDT-8 did not induce hepatotoxicity in the liver of $\mathrm{KO}$ mice, while attenuating the liver injury caused by hepatic Cpr knockout (Supplementary Figure S3). Hepatic Cpr knockout inhibits Cyp51 activities, a key enzyme of cholesterol synthesis, interferes hepatic lipid metabolism and induces hepatocytes injuries (Lorbek et al., 2015). Thus, LLDT-8 has a wider therapeutic window. 
TABLE 3 | Metabolite characteristics and abundances of LLDT-8 generated in liver microsomal incubations.

\begin{tabular}{|c|c|c|c|c|c|}
\hline \multirow[t]{2}{*}{ Metabolite } & \multirow[t]{2}{*}{$\mathrm{m} / \mathbf{z}$} & \multirow[t]{2}{*}{ Retention Time (min) } & \multicolumn{3}{|c|}{ Metabolite peak ia (counts) } \\
\hline & & & LLDT-8 (50 $\mu$ M) & LLDT-8 (25 $\mu$ M) & LLDT-8 $(12.5 \mu \mathrm{M})$ \\
\hline M1 & 391.1 & 15.98 & $1.47 \mathrm{E}+08$ & $6.63 \mathrm{E}+07$ & $4.69 \mathrm{E}+07$ \\
\hline M2 & 391.1 & 17.63 & $6.54 \mathrm{E}+07$ & $3.61 \mathrm{E}+07$ & $1.59 \mathrm{E}+07$ \\
\hline LLDT-8 & 375.1 & 18.49 & - & - & - \\
\hline
\end{tabular}

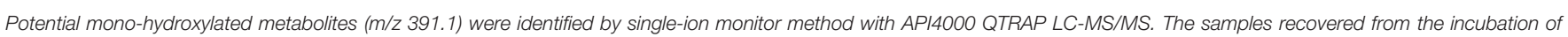

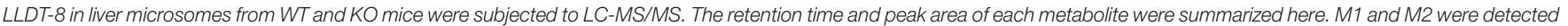
at three LLDT-8 concentration levels, and their mass spectrometric response levels (Metabolite peak area) increased with increasing LLDT-8 concentration (12.5-50 $\mu$ M).

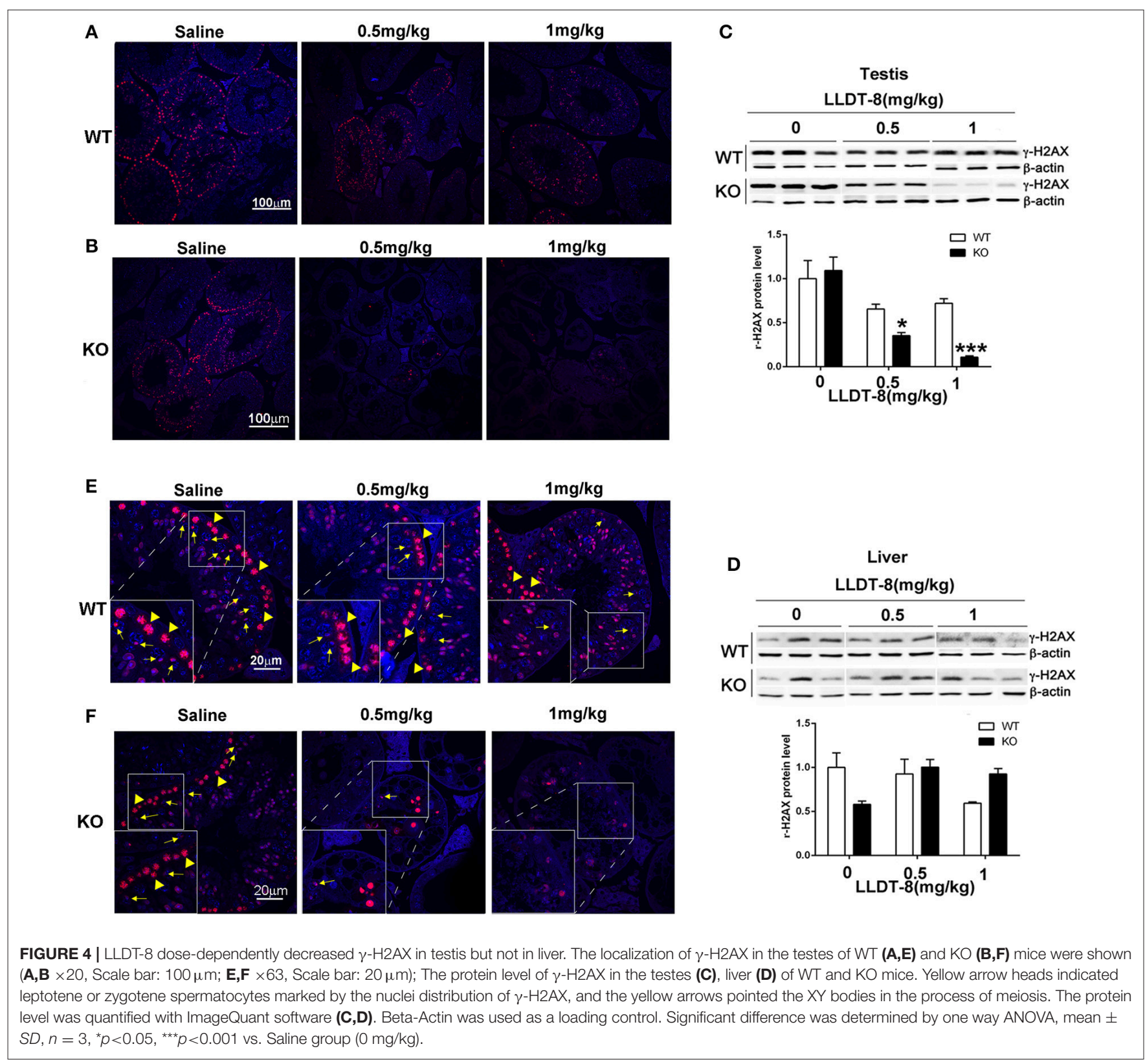

Hydroxylation via CYP450s and the subsequent glucuronidation, sulfation, and glutathione conjugation is the primary phase I/II elimination pathways of triptolide
(Du et al., 2011). We only found positive signal of potential mono-hydroxylated metabolites of LLDT-8 (m/z: 391.1) in WT mice, actively supporting the role of hepatic cyp450s in the 


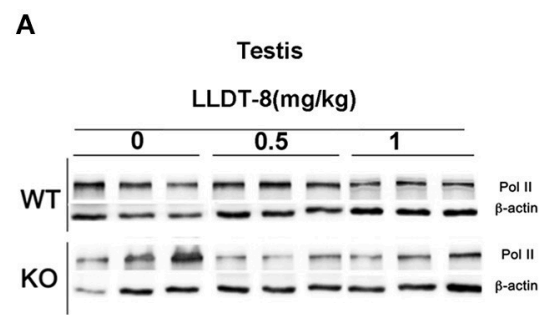

B

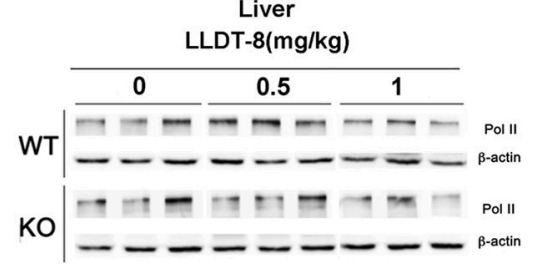

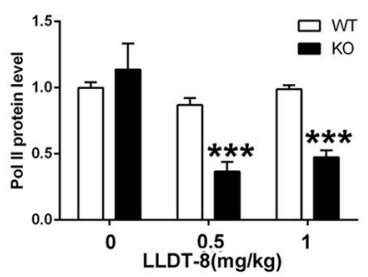

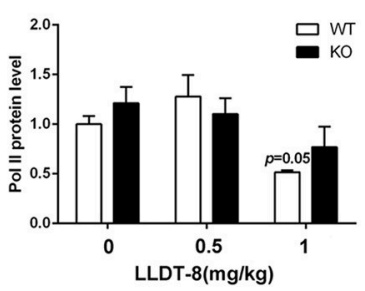

C

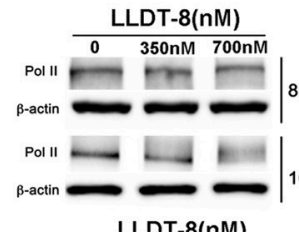

D
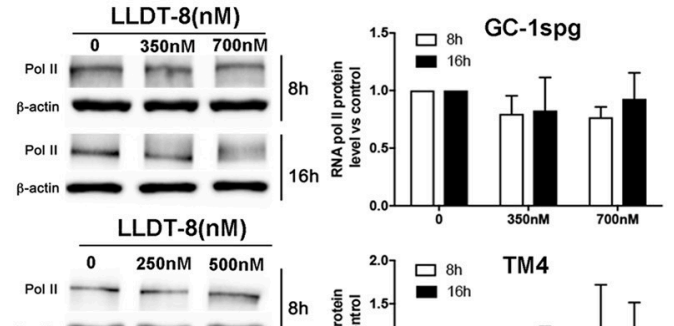

8 -actin $2 \mathrm{~h}$

Poll $\longrightarrow$

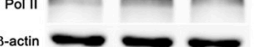

LLDT-8(nM)

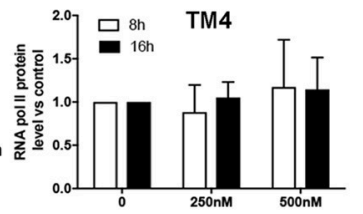

E
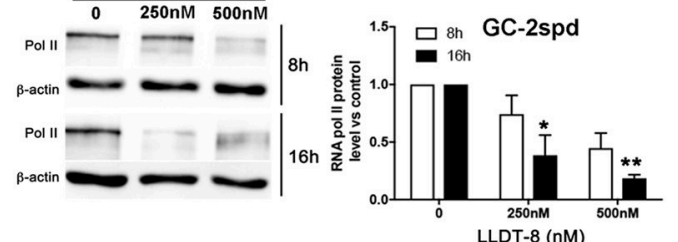

FIGURE 5 | LLDT-8 decreased RNA Pol II in vivo and in vitro. The protein levels of Pol II were detected by western blot in the testes (A), liver (B), spermatogonia-like GC-1spg cells (C), sertoli-like cells (D) and spermatocyte-like cells (E). The protein level was quantified with ImageQuant software. Beta-Actin was used as a loading control. Significant difference was determined by one way ANOVA, mean $\pm S D, n=3,{ }^{*} p<0.05,{ }^{* *} p<0.01,{ }^{* \star *} p<0.001$ vs. control group.
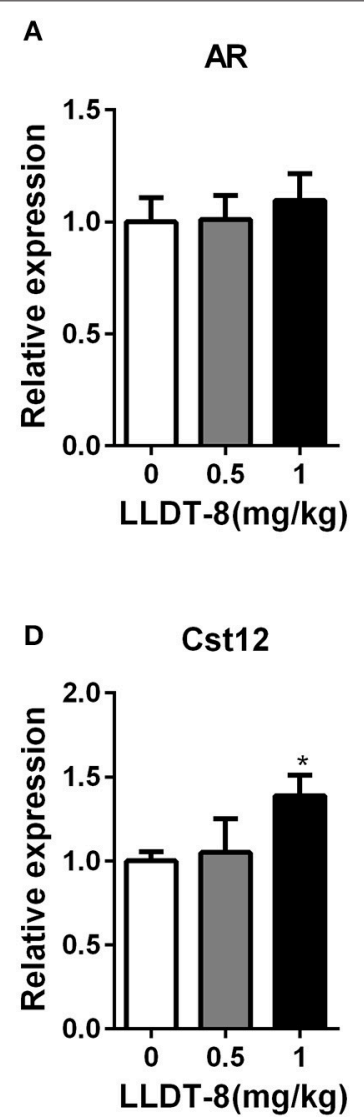

B

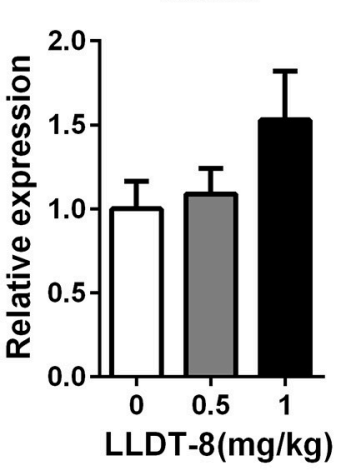

E

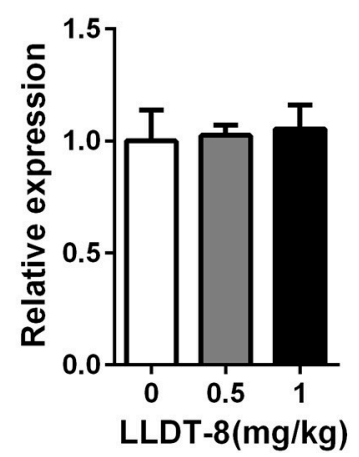

C

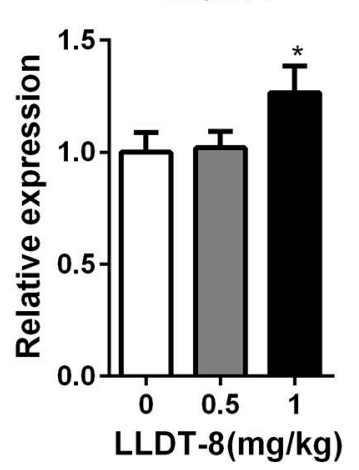

$\mathbf{F}$

FABP

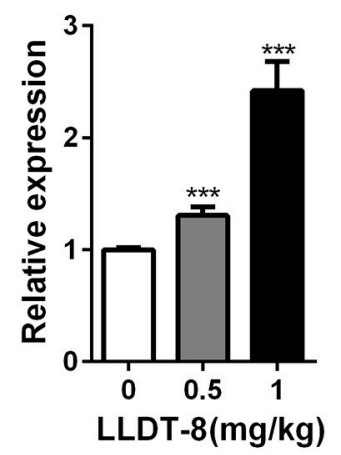

FIGURE 6 | LLDT-8 did not reduce the expression of AR-related genes in sertoli cells. AR (A), Rhox5 (B), Cldn11(C), Cst12 (D), ABP (E), and FABP (F) were determined by qPCR. Mean $\pm S D, n=3,{ }^{\star} p<0.05,{ }^{\star \star \star} p<0.001 \mathrm{vs}$. control group (0 mg/kg, Saline group). 
hydroxylation of LLDT-8. Under the context of inactivation of hepatic cyp450s, two pathways may be responsible for the clearance of LLDT-8 in KO mice. Firstly, glucuronidation et al phase II metabolism may be responsible for the elimination of LLDT08; Secondly, the remnant 5\% the hepatic cyp450s activity via cytochrome b5 as electron donor may also promote the elimination of LLDT-8 in KO mice (Riddick et al., 2013). Hydroxylation decreased the bioactivity of triptolide (Li et al., 2009). It is reasonable to deduce that hydroxylation could subdue the activities of LLDT-8. Our recent work has excluded the potentiality of hydroxylation at position 6 and 20 on LLDT-8. More work is needed to confirm the exact hydroxylation sites on LLDT-8. Additionally, chemical inhibition assay showed that Сyp3a, Сур2c, Сур2d and Cyp2e1 may be the main CYP450 isoform responsible for the metabolism of LLDT-8 in the liver of rodents. Here, clomethiazole, an inhibitor of Cyp2e1 seems to completely inhibit the metabolism of LLDT- 8 , which may be due to its less inhibition on other Cyp450s including Сур2c and Сур3a (Stresser et al., 2016).

Serine 139 phosphorylation $\mathrm{H} 2 \mathrm{AX}(\gamma-\mathrm{H} 2 \mathrm{AX})$, a marker for DNA double-strand-breaks, distributes mainly at the leptotene, zygotene, pachytene, diplotene stages of spermatocytes, and indicates the meiotic process, synapsis and XY body formation (a $\gamma$-H2AX-positive foci) (Rogakou et al., 1998). RNA polymerase II is essential for the formation of RNA granules in spermatogenesis (Pandey and Pillai, 2014). In this study, LLDT-8 decreased the protein levels of $\gamma$-H2AX and RNA pol II in the testes of KO mice. It was a reasonable assumption that the reduction of $\gamma$ $\mathrm{H} 2 \mathrm{AX}$ and Pol II in the testes of $\mathrm{KO}$ mice might be due to the loss of germ cells. Here, we observed a noticeable reduction of $\gamma$-H2AX by immunofluorescence, but no apparent loss of spermatocytes in many seminiferous tubules. Thus, we suggested that LLDT-8 may disrupt meiosis by decreasing Pol II and $\gamma$ $\mathrm{H} 2 \mathrm{AX}$ in $\mathrm{KO}$ mice, then induce the spermatocytes apoptosis. In WT mice, immunoblotting did not find a statistically significant reduction of $\gamma-\mathrm{H} 2 \mathrm{AX}$ and Pol II in the testes of WT mice, but the reduction of $\gamma-\mathrm{H} 2 \mathrm{AX}$ in the testes of WT mice was up to $40 \%$. As a derivative of triptolide, LLDT8 may induced transcription arrest through two mechanisms: (1) LLDT-8 covalently binds XPB, inhibits its DNA-dependent ATPase activity (IC50: 2,900 nM), and leads to the inhibition of Pol II-mediated transcription (Titov et al., 2011); (2) LLDT8 may trigger CDK7-dependent degradation of Pol II (Manzo et al., 2012). Thus, the reduction of $\gamma$-H2AX by LLDT- 8 and potential transcription inhibition via XPB binding may mediate the mild but significant damage in the testes of WT mice. Additionally, unlike the normal spermatogenesis in vivo, GC2spd and GC-1spg cell lines are absent of the meiosis process, and the genome is intact under normal culture condition. The increase of $\gamma$-H2AX induced by LLDT- 8 in vitro may be due to the DNA damage caused by LLDT-8 (Supplementary Figure S7).
In our study, histology investigation did not find any abnormality in Leydig cells. Importantly, LLDT-8 treatment could not reduce the expression of AR-dependent and independent genes in sertoli cells. In special, Rhox5, a lead gene for searching SCs and a major androgen response gene, was not influenced by LLDT-8 treatment, strongly supporting that AR-related signaling may be not involved in the testis injury of LLDT-8 (Supplementary Figure S8). We used mouse testis derived GC-1spg (spermatogonia-like), TM4 (Sertoli cell-like) and GC-2spd (spermatocyte-like) in vitro. Some previous reports have shown that GC-2spd cells are more sensitive to apoptosis (McKee et al., 2006; Lizama et al., 2011; Qi et al., 2016). Here, the selective reduction of RNA Pol II by LLDT-8 in GC-2spd cells may partly explain this sensitivity difference. However, the detailed mechanisms for this selectivity are still unclear.

In summary, our results indicate that hepatic P450s inactivation can influence the pharmacokinetics and distribution of LLDT-8 in vivo and may increase the risk of LLDT8-induced testicular toxicity. Inactivation or inhibition of P450s is often caused by genetic polymorphism and drugdrug interactions, which contribute to individual differences in xenobiotic metabolism and drug toxicity. Personalized prescription based on the blood concentration could be employed to maximize the therapeutic efficacy of LLDT-8 and reduce its adverse effects in the clinic use, especially in therapies that other drugs with P450 inhibitory property must be utilized along with LLDT-8.

\section{AUTHOR CONTRIBUTIONS}

Conceived and designed the experiments: ChuL, XQ, and JR. Performed the experiments: CY, YL, ML, MG, CheL, HY, ChuL, LS, LM, and CW. Contributed reagents/materials/analysis tools: $\mathrm{CY}$, ChuL, and XQ. Analyzed the data: CY, ChuL, and XQ. Wrote the paper: $\mathrm{CY}$ and $\mathrm{XQ}$.

\section{FUNDING}

This work was supported by National Natural Science Foundation of China (81102496), National Key Technologies R\&D Program (2015ZX09102005).

\section{ACKNOWLEDGMENTS}

We thank Prof. Yuanchao Li for the kind provision of high purity (5R)-5-hydroxytriptolide (99.9\%).

\section{SUPPLEMENTARY MATERIAL}

The Supplementary Material for this article can be found online at: https://www.frontiersin.org/articles/10.3389/fphar. 2017.00832/full\#supplementary-material 


\section{REFERENCES}

Ahmed, E. A., Sfeir, A., Takai, H., and Scherthan, H. (2013). Ku70 and nonhomologous end joining protect testicular cells from DNA damage. J. Cell Sci. 126(Pt 14), 3095-3104. doi: 10.1242/jcs.122788

Chen, F., Gao, X., and Shilatifard, A. (2015). Stably paused genes revealed through inhibition of transcription initiation by the TFIIH inhibitor triptolide. Genes Dev. 29, 39-47. doi: 10.1101/gad.246173.114

Corson, T. W., Cavga, H., Aberle, N., and Crews, C. M. (2011). Triptolide directly inhibits dCTP pyrophosphatase. Chembiochem 12, 1767-1773. doi: 10.1002/cbic.201100007

Du, F., Liu, T., Liu, T., Wang, Y., Wan, Y., and Xing, J. (2011). Metabolite identification of triptolide by data-dependent accurate mass spectrometric analysis in combination with online hydrogen/deuterium exchange and multiple data-mining techniques. Rapid Commun. Mass Spectrom. 25, 3167-3177. doi: 10.1002/rcm.5211

Fan, D., He, X., Bian, Y., Guo, Q., Zheng, K., Zhao, Y., et al. (2016). Triptolide Modulates TREM-1 signal pathway to inhibit the inflammatory response in rheumatoid arthritis. Int. J. Mol. Sci. 17:498. doi: 10.3390/ijms17040498

Fidler, J. M., Li, K., Chung, C., Wei, K., Ross, J. A., Gao, M., et al. (2003). PG49088 , a derivative of triptolide, causes tumor regression and sensitizes tumors to chemotherapy. Mol. Cancer Ther. 2, 855-862. Available online at: http://mct. aacrjournals.org/content/2/9/855.long

Hamer, G., Roepers-Gajadien, H. L., van Duyn-Goedhart, A., Gademan, I. S., Kal, H. B., van Buul, P. P., et al. (2003). DNA double-strand breaks and gamma-H2AX signaling in the testis. Biol. Reprod. 68, 628-634. doi: 10.1095/biolreprod.102.008672

Johnston, H., Baker, P. J., Abel, M., Charlton, H. M., Jackson, G., Fleming, L., et al. (2004). Regulation of Sertoli cell number and activity by folliclestimulating hormone and androgen during postnatal development in the mouse. Endocrinology 145, 318-329. doi: 10.1210/en.2003-1055

Kim, H. J., Ravichandran, K., Ozkok, A., Wang, Q., He, Z., Jani, A., et al. (2014). The water-soluble triptolide derivative PG490-88 protects against cisplatin-induced acute kidney injury. J. Pharmacol. Exp. Ther. 349, 518-525. doi: 10.1124/jpet.114.213769

Kitzen, J. J., de Jonge, M. J., Lamers, C. H., Eskens, F. A., van der Biessen, D., van Doorn, L., et al. (2009). Phase I dose-escalation study of F60008, a novel apoptosis inducer, in patients with advanced solid tumours. Eur. J. Cancer 45, 1764-1772. doi: 10.1016/j.ejca.2009.01.026

Kong, L. L., Zhuang, X. M., Yang, H. Y., Yuan, M., Xu, L., and Li, H. (2015). Inhibition of P-glycoprotein gene expression and function enhances triptolideinduced hepatotoxicity in mice. Sci. Rep. 5:11747. doi: 10.1038/srep11747

Kurek, D., Neagu, A., Tastemel, M., Tuysuz, N., Lehmann, J., van de Werken, H. J., et al. (2015). Endogenous WNT signals mediate BMP-induced and spontaneous differentiation of epiblast stem cells and human embryonic stem cells. Stem Cell Rep. 4, 114-128. doi: 10.1016/j.stemcr.2014.11.007

Latendresse, J. R., Warbrittion, A. R., Jonassen, H., and Creasy, D. M. (2002). Fixation of testes and eyes using a modified Davidson's fluid: comparison with Bouin's fluid and conventional Davidson's fluid. Toxicol. Pathol. 30, 524-533. doi: 10.1080/01926230290105721

Leuenroth, S. J., Bencivenga, N., Chahboune, H., Hyder, F., and Crews, C. M. (2010). Triptolide reduces cyst formation in a neonatal to adult transition Pkd1 model of ADPKD. Nephrol. Dial. Transplant. 25, 2187-2194. doi: $10.1093 / \mathrm{ndt} / \mathrm{gfp} 777$

Leuenroth, S. J., and Crews, C. M. (2008). Triptolide-induced transcriptional arrest is associated with changes in nuclear substructure. Cancer Res. 68, 5257-5266. doi: 10.1158/0008-5472.CAN-07-6207

Li, W., Liu, Y., He, Y. Q., Zhang, J. W., Gao, Y., Ge, G. B., et al. (2008). Characterization of triptolide hydroxylation by cytochrome P450 in human and rat liver microsomes. Xenobiotica 38, 1551-1565. doi: 10.1080/00498250802503359

Li, Y., Putnam-Lawson, C. A., Knapp-Hoch, H., Friel, P. J., Mitchell, D., Hively, R., et al. (2005). Immunolocalization and regulation of cystatin 12 in mouse testis and epididymis. Biol. Reprod. 73, 872-880. doi: 10.1095/biolreprod.105.040238

Li, Z., Zhou, Z. L., Miao, Z. H., Lin, L. P., Feng, H. J., Tong, L. J., et al. (2009). Design and synthesis of novel C14-hydroxyl substituted triptolide derivatives as potential selective antitumor agents. J. Med. Chem. 52, 5115-5123. doi: $10.1021 / j m 900342 \mathrm{~g}$
Liu, L., Li, G., Li, Q., Jin, Z., Zhang, L., Zhou, J., et al. (2013a). Triptolide induces apoptosis in human leukemia cells through caspase-3-mediated ROCK1 activation and MLC phosphorylation. Cell Death Dis. 4, e941. doi: $10.1038 /$ cddis. 2013.469

Liu, Q. (2011). Triptolide and its expanding multiple pharmacological functions. Int. Immunopharmacol. 11, 377-383. doi: 10.1016/j.intimp.2011.01.012

Liu, Y., Chen, F., Wang, S., Guo, X., Shi, P., Wang, W., et al. (2013b). Low-dose triptolide in combination with idarubicin induces apoptosis in AML leukemic stem-like KGla cell line by modulation of the intrinsic and extrinsic factors. Cell Death Dis 4, e948. doi: 10.1038/cddis.2013.467

Liu, Z., Ma, L., and Zhou, G. B. (2011). The main anticancer bullets of the Chinese medicinal herb, thunder god vine. Molecules 16, 5283-5297. doi: 10.3390/molecules16065283

Lizama, C., Ludwig, A., and Moreno, R. D. (2011). Etoposide induces apoptosis and upregulation of TACE/ADAM17 and ADAM10 in an in vitro male germ cell line model. Biochim. Biophys. Acta 1813, 120-128. doi: 10.1016/j.bbamcr.2010.08.003

Lorbek, G., Perse, M., Jeruc, J., Juvan, P., Gutierrez-Mariscal, F. M., Lewinska, M., et al. (2015). Lessons from hepatocyte-specific Cyp51 knockout mice: impaired cholesterol synthesis leads to oval cell-driven liver injury. Sci. Rep. 5:8777. doi: 10.1038/srep08777

Lu, Y., Zhang, Y., Li, L., Feng, X., Ding, S., Zheng, W., et al. (2014). TAB1: a target of triptolide in macrophages. Chem. Biol. 21, 246-256. doi: 10.1016/j.chembiol.2013.12.009

Ma, B., Qi, H., Li, J., Xu, H., Chi, B., Zhu, J., et al. (2015). Triptolide disrupts fatty acids and peroxisome proliferator-activated receptor (PPAR) levels in male mice testes followed by testicular injury: a GC-MS based metabolomics study. Toxicology 336, 84-95. doi: 10.1016/j.tox.2015.07.008

Ma, W., Hu, S., Yao, G., Xie, S., Ni, M., Liu, Q., et al. (2013). An androgen receptormicrorna-29a regulatory circuitry in mouse epididymis. J. Biol. Chem. 288, 29369-29381. doi: 10.1074/jbc.M113.454066

Manzo, S. G., Zhou, Z. L., Wang, Y. Q., Marinello, J., He, J. X., Li, Y. C., et al. (2012). Natural product triptolide mediates cancer cell death by triggering CDK7dependent degradation of RNA polymerase II. Cancer Res. 72, 5363-5373. doi: 10.1158/0008-5472.CAN-12-1006

McKee, C. M., Ye, Y., and Richburg, J. H. (2006). Testicular germ cell sensitivity to TRAIL-induced apoptosis is dependent upon p53 expression and is synergistically enhanced by DR5 agonistic antibody treatment. Apoptosis 11, 2237-2250. doi: 10.1007/s10495-006-0288-1

Mujumdar, N., Mackenzie, T. N., Dudeja, V., Chugh, R., Antonoff, M. B., BorjaCacho, D., et al. (2010). Triptolide induces cell death in pancreatic cancer cells by apoptotic and autophagic pathways. Gastroenterology 139, 598-608. doi: 10.1053/j.gastro.2010.04.046

Noguchi, J., Ozawa, M., Nakai, M., Somfai, T., Kikuchi, K., Kaneko, H., et al. (2008). Affected homologous chromosome pairing and phosphorylation of testis specific histone, H2AX, in male meiosis under FKBP6 deficiency. J. Reprod. Dev. 54, 203-207. doi: 10.1262/jrd.19158

Pan, J. (2010). RNA polymerase - an important molecular target of triptolide in cancer cells. Cancer Lett. 292, 149-152. doi: 10.1016/j.canlet.2009.11.018

Pandey, R. R., and Pillai, R. S. (2014). Primary piRNA biogenesis: caught up in a Maelstrom. EMBO J. 33, 1979-1980. doi: 10.15252/embj.201489670

Patil, S., Lis, L. G., Schumacher, R. J., Norris, B. J., Morgan, M. L., Cuellar, R. A., et al. (2015). Phosphonooxymethyl prodrug of triptolide: synthesis, physicochemical characterization, and efficacy in human colon adenocarcinoma and ovarian cancer xenografts. J. Med. Chem. 58, 9334-9344. doi: 10.1021/acs.jmedchem.5b01329

Qi, B., Wang, X., Zhou, Y., Han, Q., He, L., Gong, T., et al. (2015). A renaltargeted triptolide aminoglycoside (TPAG) conjugate for lowering systemic toxicities of triptolide. Fitoterapia 103, 242-251. doi: 10.1016/j.fitote.2015. 04.008

Qi, X., Li, C., Wu, C., Yu, C., Liu, M., Gao, M., et al. (2016). Dephosphorylation of Tak1 at Ser412 greatly contributes to the spermatocyte-specific testis toxicity induced by (5R)-5-hydroxytriptolide in C57BL/6 mice. Toxicol. Res. 5, 594-601. doi: 10.1039/C5TX00409H

Riddick, D. S., Ding, X., Wolf, C. R., Porter, T. D., Pandey, A. V., Zhang, Q. Y., et al. (2013). NADPH-cytochrome P450 oxidoreductase: roles in physiology, pharmacology, and toxicology. Drug Metab. Dispos. 41, 12-23. doi: $10.1124 / \mathrm{dmd} .112 .048991$ 
Rogakou, E. P., Pilch, D. R., Orr, A. H., Ivanova, V. S., and Bonner, W. M. (1998). DNA double-stranded breaks induce histone $\mathrm{H} 2 \mathrm{AX}$ phosphorylation on serine 139. J. Biol. Chem. 273, 5858-5868. doi: 10.1074/jbc.273.10.5858

Ruan, Q., Xu, Y., Xu, R., Wang, J., Hua, Y., Wang, M., et al. (2017). The adverse effects of triptolide on the reproductive system of Caenorhabditis elegans: oogenesis impairment and decreased oocyte quality. Int. J. Mol. Sci. 18:E464. doi: 10.3390/ijms18020464

Sangwan, V., Banerjee, S., Jensen, K. M., Chen, Z., Chugh, R., Dudeja, V., et al. (2015). Primary and liver metastasis-derived cell lines from KrasG12D; Trp53R172H; Pdx-1 Cre animals undergo apoptosis in response to triptolide. Pancreas 44, 583-589. doi: 10.1097/MPA.0000000000000317

Stresser, D. M., Perloff, E. S., Mason, A. K., Blanchard, A. P., Dehal, S. S., Creegan, T. P., et al. (2016). Selective time- and NADPH-dependent inhibition of human CYP2E1 by clomethiazole. Drug Metab. Dispos. 44, 1424-1430. doi: $10.1124 / \mathrm{dmd} .116 .070193$

Su, R., Sun, M., Wang, W., Zhang, J., Zhang, L., Zhen, J., et al. (2017). A Novel Immunosuppressor, (5R)-5-Hydroxytriptolide, Alleviates Movement Disorder and Neuroinflammation in a 6-OHDA Hemiparkinsonian Rat Model. Aging Dis. 8, 31-43. doi: 10.14336/AD.2016.0929

Sumigray, K., Zhou, K., and Lechler, T. (2014). Cell-cell adhesions and cell contractility are upregulated upon desmosome disruption. PLoS ONE 9:e101824. doi: 10.1371/journal.pone.0101824

Sun, L., Li, H., Huang, X., Wang, T., Zhang, S., Yang, J., et al. (2013). Triptolide alters barrier function in renal proximal tubular cells in rats. Toxicol. Lett. 223, 96-102. doi: 10.1016/j.toxlet.2013.08.014

Tan, K. A., De Gendt, K., Atanassova, N., Walker, M., Sharpe, R. M., Saunders, P. T., et al. (2005). The role of androgens in sertoli cell proliferation and functional maturation: studies in mice with total or Sertoli cell-selective ablation of the androgen receptor. Endocrinology 146, 2674-2683. doi: 10.1210/en.2004-1630

Titov, D. V., Gilman, B., He, Q. L., Bhat, S., Low, W. K., Dang, Y., et al. (2011). XPB, a subunit of TFIIH, is a target of the natural product triptolide. Nat. Chem. Biol. 7, 182-188. doi: 10.1038/nchembio.522

Tsyrlov, I. B., Mikhailenko, V. M., and Gelboin, H. V. (1994). Isozymeand species-specific susceptibility of cDNA-expressed CYP1A P450 s to different flavonoids. Biochim. Biophys. Acta 1205, 325-335. doi: 10.1016/0167-4838(94)90252-6

Vanschoonbeek, K., Wouters, K., van der Meijden, P. E., van Gorp, P. J., Feijge, M. A., Herfs, M., et al. (2008). Anticoagulant effect of dietary fish oil in hyperlipidemia: a study of hepatic gene expression in APOE2 knock-in mice. Arterioscler. Thromb. Vasc. Biol. 28, 2023-2029. doi: 10.1161/ATVBAHA.107.156992

Villicana, C., Cruz, G., and Zurita, M. (2013). The genetic depletion or the triptolide inhibition of TFIIH in p53-deficient cells induces a JNKdependent cell death in Drosophila. J. Cell Sci .126(Pt 11), 2502-2515. doi: $10.1242 /$ jcs. 122721

Voronina, E., Seydoux, G., Sassone-Corsi, P., and Nagamori, I. (2011). RNA granules in germ cells. Cold Spring Harb. Perspect. Biol. 3:a002774. doi: $10.1101 /$ cshperspect.a002774

Wan, C., Jin, F., Du, Y., Yang, K., Yao, L., Mei, Z., et al. (2017). Genistein improves schistosomiasis liver granuloma and fibrosis via dampening NF-kB signaling in mice. Parasitol. Res. 116, 1165-1174. doi: 10.1007/s00436-017-5392-3

Wang, L., Xu, Y., Fu, L., Li, Y., and Lou, L. (2012). (5R)-5-hydroxytriptolide (LLDT-8), a novel immunosuppressant in clinical trials, exhibits potent antitumor activity via transcription inhibition. Cancer Lett. 324, 75-82. doi: 10.1016/j.canlet.2012.05.004

Wang, P. Y., Zeng, W. J., Liu, J., Wu, Y. L., Ma, Y., Zeng, Z., et al. (2017). TRC4, an improved triptolide derivative, specifically targets to truncated form of retinoid X receptor-alpha in cancer cells. Biochem. Pharmacol. 124, 19-28. doi: 10.1016/j.bcp.2016.10.014

Wang, W., Yang, Y., Xiong, Z., Kong, J., Fu, X., Shen, F., et al. (2016a). Inhibition of glycogen synthase kinase 3 beta ameliorates triptolide-induced acute cardiac injury by desensitizing mitochondrial permeability transition. Toxicol. Appl. Pharmacol. 313, 195-203. doi: 10.1016/j.taap.2016.10.007

Wang, X., Zhao, F., Lv, Z. M., Shi, W. Q., Zhang, L. Y., and Yan, M. (2016b). Triptolide disrupts the actin-based Sertoli-germ cells adherens junctions by inhibiting Rho GTPases expression. Toxicol. Appl. Pharmacol. 310, 32-40. doi: 10.1016/j.taap.2016.08.017
Willems, A., De Gendt, K., Allemeersch, J., Smith, L. B., Welsh, M., Swinnen, J. V., et al. (2010). Early effects of Sertoli cell-selective androgen receptor ablation on testicular gene expression. Int. J. Androl. 33, 507-517. doi: $10.1111 /$ j.1365-2605.2009.00964.x

Wu, L., Gu, J., Cui, H., Zhang, Q. Y., Behr, M., Fang, C., et al. (2005). Transgenic mice with a hypomorphic NADPH-cytochrome $\mathrm{P} 450$ reductase gene: effects on development, reproduction, and microsomal cytochrome P450. J. Pharmacol. Exp. Ther. 312, 35-43. doi: 10.1124/jpet.104.073353

Wu, L., Gu, J., Weng, Y., Kluetzman, K., Swiatek, P., Behr, M., et al. (2003). Conditional knockout of the mouse NADPH-cytochrome p450 reductase gene. Genesis 36, 177-181. doi: 10.1002/gene.10214

Xiao, Y., Ge, M., Xue, X., Wang, C., Wang, H., Wu, X., et al. (2008). Hepatic cytochrome P450s metabolize aristolochic acid and reduce its kidney toxicity. Kidney Int. 73, 1231-1239. doi: 10.1038/ki.2008.103

Xue, X., Gong, L., Qi, X., Wu, Y., Xing, G., Yao, J., et al. (2011). Knockout of hepatic P450 reductase aggravates triptolide-induced toxicity. Toxicol. Lett. 205, 47-54. doi: 10.1016/j.toxlet.2011.05.003

Yao, J., Li, C. G., Gong, L. K., Feng, C. C., Li, C. Z., Gao, M., et al. (2014). Hepatic cytochrome $\mathrm{P} 450$ s play a major role in monocrotaline-induced renal toxicity in mice. Acta Pharmacol. Sin. 35, 292-300. doi: 10.1038/aps.2013.145

Ye, X., Li, W., Yan, Y., Mao, C., Cai, R., Xu, H., et al. (2010). Effects of cytochrome $\mathrm{P} 4503 \mathrm{~A}$ inducer dexamethasone on the metabolism and toxicity of triptolide in rat. Toxicol. Lett. 192, 212-220. doi: 10.1016/j.toxlet.2009.10.028

Zeng, J. Z., Ma, L. F., Meng, H., Yu, H. M., Zhang, Y. K., and Guo, A. (2016). (5R)-5-hydroxytriptolide (LLDT-8) prevents collagen-induced arthritis through OPG/RANK/RANKL signaling in a rat model of rheumatoid arthritis. Exp. Ther. Med. 12, 3101-3106. doi: 10.3892/etm.2016.3739

Zhang, W., Kang, M., Zhang, T., Li, B., Liao, X., and Wang, R. (2016). Triptolide combined with radiotherapy for the treatment of nasopharyngeal carcinoma via NF-kappaB-related mechanism. Int. J. Mol. Sci. 17:2139. doi: $10.3390 /$ ijms 17122139

Zheng, C. X., Chen, Z. H., Zeng, C. H., Qin, W. S., Li, L. S., and Liu, Z. H. (2008). Triptolide protects podocytes from puromycin aminonucleoside induced injury in vivo and in vitro. Kidney Int. 74, 596-612. doi: 10.1038/ki. 2008.203

Zhou, R., Tang, W., Ren, Y. X., He, P. L., Zhang, F., Shi, L. P., et al. (2006a). (5R)-5-hydroxytriptolide attenuated collagen-induced arthritis in DBA/1 mice via suppressing interferon-gamma production and its related signaling. $J$. Pharmacol. Exp. Ther. 318, 35-44. doi: 10.1124/jpet.106.101113

Zhou, R., Wang, J. X., Tang, W., He, P. L., Yang, Y. F., Li, Y. C., et al. (2006b). (5R)5-hydroxytriptolide inhibits IFN-gamma-related signaling. Acta Pharmacol. Sin. 27, 1616-1621. doi: 10.1111/j.1745-7254.2006.00457.x

Zhou, R., Zhang, F., He, P. L., Zhou, W. L., Wu, Q. L., Xu, J. Y., et al. (2005). (5R)-5-hydroxytriptolide (LLDT-8), a novel triptolide analog mediates immunosuppressive effects in vitro and in vivo. Int. Immunopharmacol. 5, 1895-1903. doi: 10.1016/j.intimp.2005.06.009

Zhou, Z. L., Yang, Y. X., Ding, J., Li, Y. C., and Miao, Z. H. (2012). Triptolide: structural modifications, structure-activity relationships, bioactivities, clinical development and mechanisms. Nat. Prod. Rep. 29, 457-475. doi: 10.1039/c2np00088a

Zhuang, X. M., Shen, G. L., Xiao, W. B., Tan, Y., Lu, C., and Li, H. (2013). Assessment of the roles of P-glycoprotein and cytochrome P450 in triptolide-induced liver toxicity in sandwich-cultured rat hepatocyte model. Drug Metab. Dispos. 41, 2158-2165. doi: 10.1124/dmd.113. 054056

Conflict of Interest Statement: The authors declare that the research was conducted in the absence of any commercial or financial relationships that could be construed as a potential conflict of interest.

Copyright $\odot 2017$ Yu, Li, Liu, Gao, Li, Yan, Li, Sun, Mo, Wu, Qi and Ren. This is an open-access article distributed under the terms of the Creative Commons Attribution License (CC BY). The use, distribution or reproduction in other forums is permitted, provided the original author(s) or licensor are credited and that the original publication in this journal is cited, in accordance with accepted academic practice. No use, distribution or reproduction is permitted which does not comply with these terms. 